\title{
En el arca de Arreola, carne y palabra se buscan (sobre su Bestiario de 1958)*
}

Fecha de recepción: 23 de septiembre de 2014

Fecha de aprobación: 12 de noviembre de 2014

\section{Resumen:}

Este artículo es un análisis del compendio "zoológico" presente en Bestiario de Juan José Arreola. El acercamiento al universo imaginario de Arreola se aborda en primer lugar a través de la puesta en diálogo del Bestiario con el Physiologos, texto embrionario de los bestiarios de la tradición occidental y en segundo lugar a través de un análisis de texto. En esencia se pretende subrayar el modo en que los animales del bestiario (a través de su lexicalización) se encarnan en representaciones imaginarias, vinculadas éstas con los tiempos primordiales. Para tal fin estudiamos tres paradigmas clasificatorios de la carne animal que denominamos: tierra, aire, agua. Dicha clasificación pretende dar cuenta de la significación espiritual de la palabra en el libro de Arreola y a la vez reflejar la manera en que los animales del bestiario simbolizan la carne humana, hecha posible a través del lenguaje poético.

Palabras clave: Figuración literaria; zoología; símbolo; animalidad; bestiario.

* Artículo de reflexión desarrollado dentro de la unidad de investigación: Los bestiarios en la narrativa hispanoamericana, adscrita a la Maestría en Estudios ibéricos e iberoamericanos de la Universidad Stendhal-Grenoble III.

Citar: Gramusset, F. (enero-junio de 2015). En el arca de Arreola, carne y palabra se buscan(sobre su Bestiario de 1958). La Palabra (26).Páginas 85-95

\section{François Gramusset}

Université Stendhal- Grenoble III, Francia gramussetgrenoblefrancois@ gmail.com

** Doctor en literatura de la Universidad de la Sorbona-Paris IV. Profesor-investigador de literatura hispanoamericana y española en la Universidad StendhalGrenoble III. Director adjunto del laboratorio de investigación Centre des recherches sur l'imaginaire (CRI). Responsable pedagógico del Master 1 en estudios románicos, sección de español. 


\section{la palabra}

\section{In Arreola's arc,flesh and word seek each other (on his 1958 Bestiario [bestiary])}

\section{Abstract:}

This article analyzes the zoological collection present in Juan Jose Arreola's bestiary. A close look at the imaginary universe of Arreola is achieved, in the first place by establishing a conversation between the Bestiario and Physiologos, an embrionary text for bestiaries of the Western tradition; and secondly through analysis of the text. In essence, the aim is to underline the way in which, through their lexicalization, these bestiary creatures embody imaginary representations, linked to primordial times. For this purpose we study three classification paradigms of animal flesh: earth, air, water. This classification attempts to account for the spiritual significance of the word in Arreola's book, as well as to show the way in which these bestiary animals symbolize human flesh, made possible through poetic language.

Key words: Literary figurative language; zoology; symbol; animality; bestiary.

\section{Dans l'arche d'Arreola, la parole et la chaire se rejoignent. (Notes sur Bestiario, 1958)}

\section{Résumé}

Cet article analyse l'abrégé zoologique décrit par Juan José Arreola dans son livre Bestiaire. L'approche à l'univers imaginaire de l'auteur est faite d'abord par la mise en dialogue avec le Physilogos, texte embryonnaire des bestiaires qui composent la tradition littéraire d'occident, et ensuite par le biais d'une analyse de texte détaillée. On cherche à souligner comment les animaux du bestiaire (à travers leur lexicalisation) accèdent à des représentations imaginaires. On propose trois paradigmes de classification de la chaire animale, à savoir, terre, air, eau. Cette classification peut rendre compte de la signification spirituelle de la parole chez Arreola.

Mots clés: Figuration littéraire; zoologie; symbole; animalité; bestiaire. 
Descripción del objeto literario o "corpus": materia zoológica; orden y desorden de Bestiario

Bestiario (1958) del mexicano Juan José Arreola se compone de un prólogo y de 23 secuencias breves de 13 a 36 líneas. Las más llevan, a modo de título, el nombre de un animal, pero cinco llevan el nombre colectivo de un género o de una especie ("Aves de rapiña", "Felinos ", "Cérvidos", "Aves acuáticas", "Los monos"). El recorrido del índice evoca un paseo por algún jardín zoológico, con una mayoría de animales exóticos propios de zonas tropicales húmedas o secas, y en particular de especies africanas: avestruz, león, elefante, camello, cebra, jirafa, hiena, hipopótamo... Los animales hispanoamericanos son pocos: llama andina (en: "Camélidos"), boa, pato golondrino, pato cucharón y pato tepalcate (los patos: en "Aves acuáticas"), zopilote (en: "Aves de rapiña") y el ajolote. Otros forman parte de la fauna europea tradicional, apareciendo con frecuencia en los cuentos y las antiguas tradiciones culturales de occidente: el sapo, el topo, el búho, el oso, el águila, el ciervo, la garza. En busca de posibles paradigmas, damos con tres grupos que llamaremos TIERRA, AGUA, AIRE:

TIERRA: un grupo de grandes mamíferos compactos y potentes como el rinoceronte, el bisonte, el carabao, elelefante y el camello. AGUA: otro grupo de animales acuáticos como el hipopótamo, las focas, las aves acuáticas, el ajolote. AIRE: las aves de rapiña como el águila, el gavilán, el halcón, el buitre, el zopilote, y también el búho yel avestruz.

Algunos parecen ambiguos o intermedios: el hipopótamo entre tierra y agua, el avestruz entre aire y tierra, las aves acuáticas entre agua y aire. Veremos posteriormente que la potencia muscular compacta, el elemento líquido y humoral, la pluma con vocación aérea valen como ejes poéticosimbólicos capaces de ordenar parcialmente el antojadizo zoológico arreoliano. Algunos animales ocupan un espacio individual y genuino, comola santateresa de la sección "Insectiada". Se la designa como "hembra" y en efecto se justifica su aparición en la lista por ser ella, la devoradora de machos. Es el único insecto.

Dejemos el índice confesando que no podemos dar cuenta detallada del orden de los animales, en apariencia aleatorio, aunque el emplazamiento inicial y final de algunos elementos parezca significativo. Explicitaremos este dato a propósito de los dos primeros puestos, ocupados por el rinoceronte y el sapo, y de los dos últimos puestos ocupados por el ajolote y el mono que cierran el desfile. Sin embargo, es de notar que predominan los elementos del paradigma TIERRA (o: potencia muscular compacta) en la primera mitad de la lista: rinoceronte $\left(\mathrm{n}^{\circ} 1\right)$, bisonte $\left(n^{\circ} 3\right)$, carabao $\left(n^{\circ} 7\right)$, elefante $\left(n^{\circ} 11\right)$, mientras que los elementos del paradigma AGUA se concentran en la segunda mitad, y sobre todo al fin de ésta: hipopótamo $\left(\mathrm{n}^{\circ} 18\right)$, focas $\left(n^{\circ} 20\right)$, aves acuáticas $\left(n^{\circ} 21\right)$, ajolote $\left(n^{\circ} 22\right)$. Los animales plumíferos (AIRE) se intercalan en la primera mitad: aves de rapiña $\left(n^{\circ} 4\right)$, avestruz $\left(n^{\circ} 5\right)$, búho $\left(n^{\circ} 9\right)$, y reaparece al fin: aves acuáticas $\left(n^{\circ} 21\right)$.

Esta aproximación paulatina al libro tiene la virtud de destacar las excepciones, los casos que estorban las clasificaciones y nos obligan a adentrarnos más en la problemática poética, alejándonos de los pre-textos zoológicos arreolianos. Por ejemplo, el búho en el texto de Arreola, es apenas un animal real: es más bien el ave de Minerva, símbolo de sabiduría, que sólo sale de noche, es decir con la madurez del hombre. Sucede lo mismo con el ciervo, que más que pacer en los bosques primaverales aparece en el texto rodeado de la simbología cristiana medieval y de las praderas del Cántico espiritual. A estos elementos les sobra simbolismo individual, y les falta la carne animal, de tal manera que no 
caben en nuestraclasificación zoológica. Vamos a ver que la proporción de símbolo y de animalidad varía para cada elemento. Pero tendremos que ir todavía más allá de esta dualidad para escuchar a Arreola y entender cómo arraiga en la tradición antiquísima de los "bestiarios" para transformarla y dar a la bestia, como símbolo de la carne humana, la palabra que le falta.

\section{Intercambio incesante de lo figurado y de la figura: tradición propicia del Phy- siologos y universo mental de Arreola}

\section{El universo mental del Physiologos}

Bestiario de Arreola es un quténtico retoño del Physio-

probablemente en el segundo siglo de nuestra era en Egipto, que fuera en aquel entonces el centro del pensamiento cristiano incipiente. Desde el año 2005 gracias a un editor de Grenoble, disponemos de una excelente traducción al francés por Arnaud Zucker, acompañada de una introducción y unos comentarios imprescindibles. Me refiero a: Physiologos. Le bestiaire des bestiaires. Arnaud Zucker escribe:

La partie du texte physiologique qui semblait exprimer la réalité concrète (la nature animale), parce qu'elle est servie par l'ancienne loi (la lettre) et associée à elle devient une figure et une métaphore; et la partie qui paraît exprimer le sens spirituel (le message théologique), parce qu'il est servi par la nouvelle alliance qui est révélation et dévoilement (l'esprit)devient la réalité même. ${ }^{2}$ (Zucker, 2005, p.35).

Explicitemos: lo que aparece a nuestra mente moderna como descripción de la realidad natural (la animalidad zoológica) viene a ser figura o signo en el Physiologos; y lo que nos aparece como interpretación espiritual viene a ser pura cosa, la realidad misma. Lo aclara perfectamente el sabio helenista al explicar que en la literatura cristiana de los primeros siglos (traduzco):
"La naturaleza, sencillamente, no tiene sentido físico. Tiene un orden, una coherencia, una función, pero no tiene sentido" (Zucker, 2005, p.37). Así pues, la naturaleza zoológica es figura, y lo que se dice y comenta de ella para sacar su significación es realidad, porque en el Physiologos el significado precede al signo. Según Zucker, Dios y la revelación que culmina en Cristo preceden a toda criatura, situándose por encima de la creación y de la historia (Zucker, 2005). Se nos ocurre entonces que para captar el Physiologos y leerlo bien hay que tomar al pie de la palabra la fórmula de San Juan³

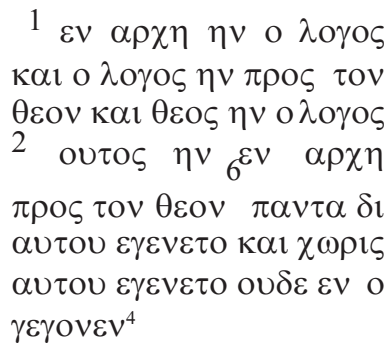

Esto implica que las criaturas, y entre ellas los animales, son figuras de la revelación, del Verbo, que constituye la primera y última realidad.

1 Physiologos, en griego $\Phi v \sigma l o \lambda o ́ \gamma o \varsigma$, es uno de los primeros tratados de historia natural del que se tenga conocimiento. Tiene apartados acerca del reino animal, mineral y vegetal. Su popularidad en mundo cristiano de la edad media se debe sin duda al carácter moralizante de sus reflexiones. Debido a su antigüedad y por ser el inspirador de los numerosos bestiarios medievales ha sido considerado como el bestiario de bestiarios en palabras de Zucker. (Zucker, 2005)

2 Traduzco: "La parte fisiológica del texto que parece expresar la realidad concreta (la naturaleza animal), siendo utilizada por la ley antigua (la palabra) y asociada a ella, llega a ser figura y metáfora; y la parte que parece expresar el sentido espiritual (el mensaje teológico), siendo utilizada por la nueva alianza que es revelación y descubrimiento (el espíritu) llega a ser la realidad misma" (Zucker, 2005, p. 35).

3 Tomamos la edición establecida por los monjes de l' Abbaye Saint-Benoît de Maredsous., \& Abbaye Sainte-Marie-Madeleine, citada en las referencias.

$4{ }^{1}$ En el principio era el Verbo, y el Verbo era con Dios, y el Verbo era Dios. ${ }^{2}$ Este era en el principio con Dios. ${ }^{3}$ Todas la cosas por él fueron hechas, y sin él nada de lo que ha sido hecho, fue hecho. (Evangelio de San Juan, 1.1-3). 


\section{El universo mental} de Arreola (visita a uncuento: "Parturient montes")

Juan José Arreola asimila la tradición derivada del Physiologos y la revierte en su problemática de poeta moderno. En su Bestiario, parece como si (pero sólo es el como si de una impresión primera) Arreola empezara con una descripción exacta y precisa, sumamente visual y eficaz, sugestiva y concreta del animal, y se dedicara luego, poco a poco, a revelar o añadir connotaciones poéticas e interpretaciones morales. Pero no es así. Desde la primera palabra impera la realidad del verbo; sentido previo y original. Pero esta realidad verbal de la que el animal es figura ya no proviene del horizonte cristiano sino de la poética arreoliana.

Este movimiento del espíritu que procedía de la especificidad del pensamiento cristiano, si bien fue singular en los siglos de su formación como híbrido original del helenismo y del judaísmo, llegó a ser lo más común en la men- te medieval europea 5 . Pero hoy día nos cuesta interiorizar esta estructura mental. A Arreola no le costaba. Hasta podemos decir que encontró en este movimiento una postura discursiva y poética particularmente adaptada a su modo de imaginar, pensar y hablar. Zucker habla de "retournement du monde" 6 (Zucker, 2005, p.33) y escribe : "Les êtres naturels ont à cœur d'incarner l'écriture et en constituent pour ainsi dire l'exégèse physique"'. Este tipo de retournement le es familiar a Arreola por cuanto constituye un topos de su espíritu. Lo vemos con toda claridad en el primer cuento de su Confabulario, titulado con una cita del Arte poética de Horacio: "Parturient montes". ra sutil de este cuento consiste en tomar narrativamente al pie de la letra la figura horaciana del ridículo ratoncito parido por las montañas enormes. Según Horacio, es ridículo valerse de un estilo épico o pomposo para evocar un suceso trivial; hay que ajustar el estilo y el género al tema. De no ser así, el poeta se ridiculizará y la montaña dará a luz a un ratón (Horacio, 1886).
En el cuento de Arreola habla un yo, el de un hombre apremiado por la gente que cree que él se sabe una nueva versión del parto de las montañas; y el hombre, en medio de la calle, se ve forzado ainiciar el cuento, aunque se trata de un malentendido y no sabe nada nuevo, hasta que de pronto, siente una presencia viva y tibia en su axila y saca, ante la muchedumbre maravillada, un ratoncito, encarnación de la novedad esperada. Nuestro resumen del cuento es suficiente para mostrar cómo Arreola toma primero la parábola horaciana al pie de la letra, intercambiando lo literal y lo figurado. Pero ahí no se terminael juego de inversión, y el desenlace (que no contamos todavía) trae otro retournement, otra inversión, de modo que el ratón viene otra vez a simbolizar la obra, la creación literaria. El cuento, que parecía arrancar como una leyenda cosmogenética y continuar como un chiste de prestidigitador, se revela conforme a su título ("Parturient montes") y a la cita horaciana que lo sigue "...nascetur ridiculus mus" (Horacio, 1886, p.139.). En esencia, un arte poética ${ }^{10}$. El vaivén imper-

\footnotetext{
Véase: McCulloch, F. (1960). Mediaeval Latin and French bestiaries. Chapel Hill: University of North Carolina Press.

Es decir: inversión (o : vuelco ; o : voltereta) del mundo.

Traduzco al castellano: "Los seres naturales tienen gran interés en encarnar laescritura y constituyen por asídecirlo, la exégesis fisica" (Zucker, 2005, p.33).

8 "Parturient montes", en: Arreola, J. J. (1997). Narrativa completa. México: Alfaguara, p. 189-191.

9 Traduzco: "La montana dará a luz a un ridículo ratón".

10 Desde luego, el programa poético de Arreola es paradójico y al reconocer la tradición de la que emerge (Horacio), rompe también con ella: véase el artículo de Felipe Vargas: Vásquez, F. (2001). Juan José Arreola: la imposibilidad de la escritura. Madrid: Universidad Complutense de Madrid. Recuperado el 25 de Julio de 2012 de http:// www.ucm.es/info/especulo/numero18/arreola.html.
} 
ceptible y el rebote fulgurante son propios del espíritu arreoliano, que encuentra en la tradición del Physiologos un medio ambiente discursivo y poético ideal, sumamente propicio a sus brincos y volteretas.

\section{Ejemplo del sapo y elucidación del prólogo}

Acerquémonos al texto $\mathrm{y}$ consideremos el caso del sapo, que es el segundo animal del Bestiario. Todo aficionado a los animales, todo conocedor del campo se queda admirado ante la descripción arreoliana y se dice: “¡Esto es! ¡Así es!”. La pertinencia y la exactitud, lafuerza sugestiva nos proyec-

tan de pronto delante de un sapo verdadero, delante del sapo en su esencia gráfica y su presencia carnal, delante de su realidad más evidente y genuina. Ante esta clase de acierto poético se suele hablar, con demasiada facilidad, de "magia". No se trata de magia. Se trata de arte. Pero el lenguaje artístico, como todo lenguaje se puede escuchar y entender. "Salta de vez en cuando, sólo para comprobar su ra- dical estático (...) Prensado en un bloque de lodo frío, el sapo se sumerge en el invierno como una lamentable crisálida..." (Arreola, 1958, p. 81).
Esta síntesis admirable de las sensaciones de inmovilidad, de densidad pesada, de frialdad húmeda que infunde el sapo a quien lo observa, aunque procede de una agudísima capacidad de observación naturalista, no hace más que envolver el rasgo esencial elegido por Arreola, porque este rasgo constituye de antemano el centro del cristal semiológico en la formación textual. Este rasgo es el "latido". Quien haya observado de veras un sapo vivo habrá notado el ritmo regular de sus costados que se hinchan y deshinchan pausadamente. Y parece como si los saltos del sapo no fueran más que la exteriorización gestual de esta respiración impresionante. Salto, latido, corazón. Rescatemos la integridad del texto que habíamos truncado: "Salta de vez en cuando, sólo para comprobar su radical estático. El salto tiene algo de latido: viéndolo bien, el sapo es todo corazón. Prensado en un bloque de lodo frío, el sapo se sumerge en el invierno como una lamentable crisálida..."11 (Arreola, 1958, p.81).

El latido remite al corazón, núcleo de la viñeta arreoliana dedicada al sapo, como aparece a todas luces en su segunda parte: "En su actitud de esfinge hay una secreta pro- posición de canje, y la fealdad del sapo aparece ante nosotros con una abrumadora cualidad de espejo" (Arreola, 1958, p.81). Los animales de Arreola son epifánicos, son manifestaciones de la condición humana tal como la vive Arreola, figuras-espejos de la esencia del hombre. El sapo re-presenta el patético rebajamiento, el envilecimiento y la caída del príncipe azul de la creación, del hombre, convertido desde siempre y para siempre en un amante feo y odiado, que espera pacientemente su imposible redención, su "metamorfosis", escribe Arreola.

Arreola se ajusta perfectamente a la lógica del Physiologos tal como la describe Zucker: “...l'histoire naturelle des animaux se raconte à partir de la signification spirituelle qu'ils revêtent et le portrait au naturel apparaît logiquement postérieur à la formule de l'exégèse" 12 (Zucher, 2005, p. 22). La primera parte descriptiva de la viñeta arreoliana venía de antemano estructurada y dictada por la "interpretación" final del sapo. De tal modo que conviene formularlo al revés: la realidad, aquí, es la condición del hombre que ama, sufre y aguarda en silencio. El sapo es figura de esta condición patética. Asípode-

11 El subrayado es nuestro.

12 Traduzco al castellano: “... la historia natural de los animales se cuenta a partir de la significación espiritual que asumen y el retrato al natural aparece de manera lógica y posterior a la formulación de la exégesis" (Zucker, 2005 p. 22). 
mos entender el prólogo del Bestiario en su singularidad enunciativa y léxica.

El prólogo se dirige a un "tú" anónimo, al lector, invitándole una vez a saludar ("Saluda con todo tu corazón...") y tres veces a amar. Sólo que el objeto del amor y destinatario del saludo es un ser miserable: "prójimo desmerecido y chancletas", "esperpento de butifarra", "prójimo porcino y gallináceo", "prójima (...) con piyama de vaca" (Arreola, 1958, p.80). De una vez por todas, Arreola nos dice cómo recibir y leer su Bestiario. Es una invitación a amar a un ser "maloliente", un compendio de animalidad con "mano de pescado muerto", "mirada de perro" etc. (Arreola, 1958, p.80).

A este ser hay que saludarle, porque espera una respuesta: "te entrega su credencial de gelatina, la mano...". Espera la mirada, el ademán, la actitud de reconocimiento que le saque del envilecimiento de la rutina doméstica y le devuelva mágicamente al hombre-sapo la humanidad perdida. Eldesenlace del cuento ya aludido, Parturient montes, no dice otra cosa: el cuentista apremiado ha sabido salir del apuro gracias a la mirada enamorada de una señora, fascinada por el juglar, al que ha servido de Musa inspiradora. Tras el acto improvisado, el juglar se le acerca embelesado y le obsequia el ratoncito milagroso, pero la señora: "Tiene un gato, me dice, y vive con su marido en un departamento de lujo. Sencillamente, se propone darles una pequeña sorpresa. Nadie sabe allí lo que significa un ratón"13 (Arreola, 1958, p. 191).

El poeta es este sapo, el único que se acuerda de que fue, como todos, en su esencia eterna, príncipe, o corazón... ¿Cuándo? En el Edén antes del exilio, o fuera de la caverna de Platón... pero nunca en la existencia histórica de los hombres. A pesar de todo, se acuerda solitario y aguarda en silencio, con su salto listo, por dentro. El salto de la palabra viva.

Paradigmas de la carne animal: tierra musculosa, pluma liviana y humedad viscosa

\section{Presencia del arkê en la mole muscular}

El primer animal del desfile es el rinoceronte ${ }^{14}\left(\mathrm{n}^{\circ} 1\right)$, seguido de cerca por otros mamíferos musculosos, potentes y macizos: el bisonte $\left(\mathrm{n}^{\circ} 3\right)$, el carabao $\left(n^{\circ} 7\right)$, el elefante $\left(n^{\circ}\right.$ 11) etc. En casi todas estas viñetas asoma una referencia ex- plícita a un arkê, es decir a un tiempo primordial más allá del tiempo, un in illo tempore de la fundación del mundo:

El rinoceronte, aunque es un animal mecánico, una máquina blindada, un caballero medieval en su armadura oxidada, no pertenece a los tiempos del triunfo de la industria y del armamento mecánico: "Ha sido armado en los derrumbaderos de laprehistoria, con láminas de cuero troqueladas bajo la presión de los niveles geológicos" (Arreola, 1958, p. 86).

El bisonte, también procede deun arkê geológico: "Elhombre emboscado arrojó flecha tras flecha y cayeron uno por uno los bisontes", "Parecían modificaciones de la corteza terrestre con ese aire individual de pequeñas montañas", "Un día se vieron pocos y se refugiaron en el último redil cuaternario" (Arreola, 1958, p.91).

El carabao, una suerte de bovino asiático, se vincula con otro arkê, oriental por supuesto: "Mucho antes de las hordas capitaneadas porel Can de los Tártaros, las llanuras de occidente fueron invadidas por inmensos tropeles de bovinos. Los extremos de ese contingente se incluyeron

13 El subrayado es nuestro.

14 En Animales en Confabulario, reaparecerá el rinoceronte en un cuento epónimo, añadiéndose al ratón de "Parturient montes", a la migala de "La migala", a las hormigas de "El prodigioso miligramo" y a la mujer de "Una mujer amaestrada". 
en el nuevo paisaje, perdiendo poco a poco las características que ahora nos devuelve la contemplación del carabao" (Arreola, 1958, p. 94). Es decir que el carabao conserva las características de la horda primordial, del tiempo en que la carne era signo y el signo carne porque "los cuernos [...] descienden $[. .$.$] en una doble$ y amplia curvatura que parece escribir en el aire la redonda palabra carabao" (Arreola, 1958,p.94).

Las primeras palabras para evocar el elefante son éstas: "Viene desde el fondo de las edades y es el último modelo terrestre de maquinaria pesada [...] Aunque de pura vejez hereditaria son calvos de nacimiento, la congelación siberiana nos ha devuelto algunos ejemplares lanudos" (Arreola, 1958, p. 105). Como vemos el elefante arreoliano es más bien mamut, es decir fósil, presencia extraviada de un tiempo inmemorial. Él también tiene la virtud de ser signo de carne, o carne semiológica, gracias al marfil de sus colmillos en los que "la paciente fantasía de los chinos ha labrado todos los sueños formales del elefante"(Arreola, 1958, p. 105).

Hasta la cebra veloz es pura mole muscular salida de los tiempos prehistóricos: "Sólo el caballo Przewalski, modelo superviviente del arte rupestre, alude un poco al rigor formal de la cebra"(Arreola, 1958, p. 106).
Pero el hipopótamo también aparece plástica y geológicamente como materia de paisaje: "Con esa masa dearcilla original dan ganas de modelar una nube de pájaros, un ejército de ratones que la distribuyan porelbosque..."(Arreola, 1958, p.109).

Así pues, la potente mole muscular de los grandes animales remite, para Arreola, a un tiempo original y elemental. En aquel entonces lo mineral y lo biológico todavía no se habían diferenciado del todo, animales, paisajes y signos eran una misma cosa, carne y nombre se redondeaban en el símbolo de la figura caligráfica de cuerno o marfil, recortada sobre el horizonte de las grandes llanuras. Los grandes mamíferos remiten para él a un arkê perdido que persiste en unos fósiles vivos, cicatrices, enigmas para todos los humanos menos para Arreola. Como el sapo son esfinges y siguen preguntándole a Edipo lo que sabe sin saber.

\section{La pluma aérea: traición al cielo y disfrute de la caída}

No dedicaremos mucho espacio a este apartado porque, si las aves originan sabrosísimas viñetas, no son difíciles de descifrar. Los pájaros son habitantes del cielo. Tienen vocación aérea, celestial. Interpretemos: sus plumas habrían de servirles (como el corazón- salto al sapo y la fuerza al rinoceronte) para superar el tiempo, el exilio existencial, la rutina. En breve, la pluma o el vuelo simbolizan el deseo del alma. Por eso tan perfectamente (tan irónicamente) las aves de Arreola ilustran las formas irrisorias y hasta obscenas de la renuncia a lo mejor de sí. Son formas oximóricas. El avestruz tiene tanta ola de pluma, tanto encaje espumoso, tanto adorno abullonado, sedoso y vistoso... tiene tanto vestido de pluma... para enseñar más y mejor el culo. Burguesa obscena.

Las aves acuáticas casi repiten en escala menor el mismo paradigma, con el añadido de la charca que los alimenta: "lucen en las plumas un esplendor de bisutería" y se nutren "de pequeñas putrefacciones". "Hembras y machos vienen y van por el salón, apostando a quién los cruza con más contoneo. Impermeables a más no poder, ignoran la realidad del agua en que viven" (Arreola, 1958, p. 124).

Las aves de rapiña disfrutan con gusto, en realidad, de las comodidades del gallinero donde viven encerradas lejos del cielo que Dios les tenía prometido. Les basta salvar aristocráticamente la jerarquía y cagar en la cabeza de algún inferior en el escalafón del gallinero. De pronto se pregunta el lector a quién alude Arreola aquí. Puede que sea a los reli- 
giosos y eclesiásticos, como lo sugiere la isotopía léxica (celda monástica-contemplación del cielo-fraile silencioso). Puede que sea a los aristócratas, gen-

te de guerra altanera, con el recurso estilístico del blasón

tradicional y de la cetrería. "Se acabaron para siempre la libertad entre la nube y el peñasco"(Arreola, 1958,p. 125).

Apenas escapa el búho de los garfios de la sorna arreoliana, al depararnos un festival de inversiones y vuelcos conceptistas: "Antes de devorarlas, el búho digiere mentalmente a sus presas. Nunca se hace cargo de una rata entera si no se ha formado un previo concepto de cada una de sus partes" (Arreola, 1958, p. 131). La evocación del búho, tan visual y sugestiva, es conforme a la lógica que describimos al principio. Viene desde el principio enteramente sometida a la "realidad" arreoliana, es decir al significado del que el ave es el significante. El búho es el ave de Minerva, emblema de la sabiduría, de la filosofía y del gremio filosófico. Es el hombre en su ambición de saber, es el intelecto humano que Arreola remite tajantemente, y con su ironía habitual, a lo más trivial de la carne del ave cuando digiere al ratón. Pensar: "operación analítica de un lento devenir intestinal (...) silogismos oscuros que van a dar en la nada" (Arreola, 1958, p. 135). El estilo oximórico de Arreola le da a la pluma una connotación escatológica: obscena caída consentida de una vocación celestial rebajada a lo más terrenal y repugnante, el excremento.

\section{Humedad viscosa del sexo}

Las bestias húmedas son pocas, hipopótamo $\left(\mathrm{n}^{\circ} 18\right)$, focas $\left(n^{\circ} 20\right)$, aves acuáticas $\left(n^{\circ} 21\right)$, ajolote $\left(n^{\circ} 22\right)$ y cierran el desfile zoológico arreoliano. Dos de sus elementos van compartidos con otros paradigmas: el hipopótamo con el de los grandes animales musculares, las aves acuáticas con el del grupo plumífero. No obstante, las focas y el ajolote le confieren una densidad que compensa la escasez de la materia.

A pesar de su nombre, difícilmente se puede decir si las focas son masculinas $\mathrm{o}$ femeninas. Tienen una "blandura musculosa" pero "baten el agua con duras palmadas". Son a la vez "perros mutilados" de signo masculino, y "palomas desaladas" de signo femenino. Y aunque "se deslizan por las frescas entrañas del agua virgen con movimiento flagelo de zoospermos" no adquieren por ello ninguna virilidad. Son más bienambiguas y proteiformes: "Criaturas de vida infusa en un barro de forma primaria, con probabilidades de pez, de reptil, de ave y de cuadrúpedo" (Arreola, 1958, p. 139).

Es de notar la singular implicación personal del enunciador en la viñeta de las focas: "He visto el quehacer incesante de las focas. He oído sus gritos de júbilo, sus risotadas procaces, sus falsos llamados de náufrago. Una gota de agua me salpica la boca"'15 (Arreola, 1958, p. 140). Atrevámonos a sugerirque sele hacela boca... agua, porque las focas son carne que goza. Encarnan el puro juego erótico. Juegan al sexo como se juega al baloncesto. De ahí la envidia y el asco del enunciador que insiste en la consistencia húmeda y blanda del animal y de su entorno (blandura-oleaje-aguaresbalan-viscosas-gelatina-relamiéndose-se deslizan-lingotes de goma-barro-jabones) y ve en ellas el espectáculo de la mera carne libidinosa. Finalmente las compara con "grises y manoseados jabones de olor intenso y repulsivo". Las focas hablan a Juan José Arreola del erotismo como espectáculo de la carne y, cuando aparece finalmente la expresión "las hermanas amaestradas" para hablar de las focas de los circos, pensamos en el cuento "Una mujer amaestrada" (Arreola, 1958, p. 142). La analogía es evidente: en ambos casos tenemos un contex- 
to de espectáculo callejero y el enunciador no puede evitar una fuerte implicación personal transgresiva. En el cuento, la mujer amaestrada baila y reparte besos, como un pobre animal erótico- artístico. El espectador-narrador se olvida de las convenciones(sociales, artísticas), se deja seducir, ingresa en el círculo de tiza y empieza a bailar con la mujer amaestrada como si fuera una persona. De la misma manera, el cuentista enamorado de "Parturient montes" obsequia el ratoncito a la señora, olvidándose de las convenciones del (des)encuentro literario. Y de la misma manera las focas amaestradas, las del circo, obsequian al público su vocación erótica bajo la forma de diversos simulacros artísticos: "sostienen una esfera de cristal en la punta de la nariz", "dan saltos de caballo sobre el tablero de ajedrez", "soplan por una hilera de flautas los primeros compases de la Pasión según San Mateo" (Arreola, 1958, p. 192). Hace tiempo que el eros, el arte y el espectáculo van unidos. Pero el amor es otra cosa, más peligrosa y más misteriosa. Aquí, Arreola se las da de moralista recordando que el espacio del arte, a duras penas concedido por los poderes ${ }^{16}$, es el espacio público de la re-presentación, limitado por el círculo de tiza de unas convenciones. Para él, la car- ne pública es triste comotodo simulacro y en el arte el amor no tiene más lugar que el del como si. No tiene más presencia que el de lare-presentación.

El penúltimo animal del desfile es el ajolote y nos dará materia para la conclusión de este estudio. El ajolote es el animal más mexicano del Bestiario y él también forma parte del paradigma húmedo por ser "sirenita de los charcos mexicanos" (Arreola, 1958, p. 168).

\section{A modo de conclusión: el ajolote... y los monos finales}

El ajolote es a la vez "un lingam de transparente alusión genital" y uno de los poquísimos animales cuyas hembras padecen "el ciclo de las catástrofes biológicas más o menos menstruales" (Arreola, 1958, p. 169). En esta viñeta del ajolote asoma un tono nuevo, hasta ahora ocultado por el genio irónico y gráfico de Arreola. Se trata del decir, de la enunciación. Ya suspiraba Arreola al fin de "Las focas": "¿Pero qué decir de las hermanas amaestradas, de las focas de circo..." (Arreola, 1958, p. 169). Y no contestaba. No había nada más que decir para superar el silencio de la letra, insuperable. Ahora le cuesta hablar del ajolote y el estilo se hace didáctico; se siente el coste de lainvestigación, el peso del recurso a las autoridades capaces de respaldar el esfuerzo enunciativo: "Acerca de los ajolotes sólo dispongo de dos informaciones..."(Arreola, 1958, p. 170). Estas autoridades son Bernardino de Sahagún y la madre de Arreola $^{17}$, respaldados al fin de la viñeta por Nemilov y Jean Rostand. A lo largo del Bestiario han venido desapareciendo los animales como pre-texto, ocasión de un decir, para dejar al desnudo la pura carne humana dolorida y violentada, erguida en su deseo y herida, sangrienta en su destino. Se habla de una señora "mortalmente preñada de ajolotes", de otra violada, y de un "ciclo de catástrofes" (Arreola, 1958, p. 171). A la hora de concluir, Arreola convoca otros orígenes, más próximos y más íntimos. He aquí que su genealogía doble, (una ibérica, masculina y docta y otra americana, femenina y popular), le sirve para animarse a la confrontación de la carne sin libertad con la palabra sin gozo.

La última viñeta es la de "Los monos" en la que sale el único animal con nombre, puesto que Wolfgang Köhler ${ }^{18}$ le llamó Mono a un chimpancé al que trataba de hacer pensar. Esta última viñeta va de-

16 Véase la violencia amenazadora de la policía y del público en ambos cuentos.

17 "Una: el autor de Las cosas de Nueva España; otra: la autora de mis días" (Arreola, 1958, p. 171).

18 Ver: Köhler, W. (1917). Intelligenzprüfungen an Anthropoiden: 1. Berlin: Kgl. Akad. d. Wiss. 
sarrollando en un discurso simétrico la figura de un mono que rechaza la libertad de la conciencia para gozar en su jaula "una pensión vitalicia de frutas al alcance de su mano", y la de un sabio cuya "razón fracasa en la captura de inalcanzables frutas metafísicas" (Arreola, 1958, p.185). Aparece al fin que el sabio profesor, a pesar de su fracaso metafísico, se consoló en su propia jaula intelectual con las dos frutas de "fama y fortuna".
Lo que busca Arreola en su bestiario es la clave de la carne humana que los animales simbolizan, y su esfuerzo poético consiste en darle a cada bestia, su estatua y estatura de palabra. Al fin, temáticamente, carne (callada) y palabra (desangelada) siguen mirándose desde sendas catástrofes, separadas. Pero poéticamente flota un arca, un libro, una obra donde se rescatan unos cuantos animales verbales. El arca arreoliana es la unidad al- canzada al juntarse el significante carnal arcaico y erótico, la bestia, con su significado espiritual y hablante, el hombre. El arca tierna e irónica de Arreola se llama Bestiario y sigue navegando por las aguas del siglo XXI, que siguen subiendo ¿Seguiremos bogando a bordo, en espera de la vuelta de la paloma, con su ramo de olivo?

\section{Referencias}

Abbaye Saint-Benoît de Maredsous., \& Abbaye Sainte-Marie-Madeleine d'Hautecombe. (1992). La sainte Bible. Paris: Brepols.

Arreola, J. J. (1958). Bestiario. México: Universidad autónoma de México.

Arreola, J. J. (1997). Narrativa completa. México: Alfaguara.

Horace, Q., \& Albert, M. (1886). Q. Horatii Flacci Epistula ad Pisones de arte poetica: Horace, art poétique, texte Latin. Paris: Librairie Hachette.

Köhler, W. (1917). Intelligenzprüfungen an Anthropoiden: 1. Berlin: Kgl. Akad. d. Wiss.

McCulloch, F. (1960). Mediaeval Latin and French bestiaries. Chapel Hill: University of North Carolina Press.

Vásquez, F. (2001). Juan José Arreola: la imposibilidad de la escritura. Madrid: Universidad Complutense de Madrid. Recuperado de http://www.ucm.es/info/especulo/numero18/arreola.html.

Zucker, A. (2004). Physiologos: Le bestiaire des bestiaires. Grenoble: J. Millon. 